RESEARCH REPORT

\title{
Childhood abuse and risk of smoking onset
}

\author{
H B Nichols, B L Harlow
}

J Epidemiol Community Health 2004;58:402-406. doi: 10.1136/jech.2003.008870

See end of article for authors' affiliations

.....................

Correspondence to: Dr B L Harlow, Obstetrics and Gynecology Epidemiology Center, Brigham and Women's Hospital, 221 Longwood Avenue, Boston, MA 02115, USA; bharlow@ rics.bwh.harvard.edu

Accepted for publication 29 July 2003

\begin{abstract}
Study objective: To determine the association between childhood abuse and becoming a smoker. Design: Retrospective cohort study. Setting: Boston, Massachusetts.

Participants: 722 women aged 36-45 years who completed the baseline questionnaire for the Harvard study of moods and cycles and the survey of interpersonal relationships.

Main results: Women who experienced either physical or sexual abuse as a child were $40 \%$ more likely to begin smoking compared with women with no history of abuse (95\% Cl 1.0 to 2.0$)$. Virtually all of this association was confined to sexual abuse $(O R=2.2,95 \% \mathrm{Cl} 1.1$ to 4.3$)$ as compared with physical abuse $(\mathrm{OR}=0.7,95 \% \mathrm{Cl} 0.7$ to 1.6 ). However, the joint effect of experiencing both physical and sexual abuse as a child led to a 3.5-fold increase in the likelihood of becoming a smoker $(95 \% \mathrm{Cl} 1.3$ to 9.4$)$ compared with women who did not experience any childhood abuse after adjustment for religion, social class, and poverty.

Conclusions: Women who experience childhood abuse, even in the absence of depression, are at increased risk of becoming cigarette smokers.
\end{abstract}

$\mathrm{T}$ he tobacco epidemic is currently responsible for 4.9 million deaths per year worldwide. ${ }^{1}$ In 2000 , the prevalence of smoking among American high school senior girls was 29.7\%. Most adult smokers start their smoking practices before age 18. Therefore, it is critical that early life risk factors for smoking initiation be identified and confronted. ${ }^{2}$ In 1998, the US Department of Health and Human Services reported that the number of children subject to childhood abuse exceeded $900000 .^{3}$ This fact, combined with the knowledge that on any given day 5000 youths experiment with cigarette smoking, provides an incentive to understand the association of childhood abuse and smoking inception. ${ }^{4}$

Childhood victimisation has repeatedly been shown to increase risk for adverse health behaviours. ${ }^{5}$ Moeller et al found that adult women who reported childhood abuse were significantly more likely to report alcoholism, excessive drug use, obesity, and/or being underweight. ${ }^{6}$ In addition to behaviour, physical health and psychological wellbeing are negatively affected by a history of childhood abuse. Adverse effects include, but are not limited to, frequent head and stomach aches, gynaecological problems, difficulty sleeping, poor confidence, depression, suicidal ideology, and learning problems. $^{6-12}$

Previous research has attempted to investigate the association of childhood victimisation and smoking, but has been limited by definitions of abuse that are restricted to one or two survey questions that ask whether abuse has ever occurred..$^{78}$ In addition, childhood abuse is often combined with adolescent abuse, a problematic issue as adolescence generally encompasses the age of smoking onset and temporal relations cannot be determined. ${ }^{913}$ Although previous investigations strongly suggest that early life abuse is a significant predictor of smoking initiation, more carefully assessed exposure and outcome measures are needed.

We sought to determine, in addition to the experience of abuse, the extent to which fear of abuse may play a significant part in predicting smoking onset as well. To test the hypothesis that childhood abuse is a risk factor for cigarette smoking, we investigated the association of childhood abuse and smoking within a cohort of adult women who lived in and around Boston, MA.

\section{METHODS}

The Harvard study of moods and cycles is a prospective cohort study designed to evaluate the relation between major depression and ovarian function. Between 1995 and 1997, a random sample of 6228 women between the ages of 36 and 45 was identified using Massachusetts Town Books. This sample received an initial screening questionnaire designed to assess menstrual status and depressive symptoms using the Center for Epidemiologic Studies depression scale (CESD). Study populations with and without depression were defined based on CES-D scores and subsequent in-person interviews conducted with the structured clinical interview for DSM-IV disorders (SCID). Ultimately, a cohort of 332 depressed and 644 non-depressed women $(n=976)$ gave written consent and was formally enrolled. Further details on study enrolment and methods can be found elsewhere. ${ }^{14}$ This distribution reflected the lifetime prevalence of depression among women in the general population. ${ }^{15}$

In 1999, as part of a substudy of violent victimisation and major depression under the moods and cycles protocol, a self administered survey of interpersonal relationships was mailed to 907 active study participants. This survey was designed to assess violent victimisation and lifetime socioeconomic position and was jointly developed by researchers from Brown University, the Harvard School of Public Health, and Brigham and Women's Hospital. ${ }^{16}$ The survey was derived from the conflict tactics scale and the pregnancy abuse assessment screen and additionally addresses witnessing violent threats or acts and life stage at exposure (that is, childhood, adolescence, and adulthood). Of 907 women, 733 $(81 \%)$ participants appropriately completed and returned the survey. Participants' responses indicate frequency of abuse specific and life stage specific acts or threats. Frequency categories include: never, a few times or less, or more than a few times. A separate consent form was not required as completion and return of the survey implied consent.

To evaluate the relation between childhood victimisation and cigarette smoking, we conducted a retrospective cohort study using the survey of interpersonal relationships and information on smoking status collected at study enrolment. During data collection, we made the distinction between 
experienced childhood abuse and feared childhood abuse. Within these two categories of victimisation, participants were classified as subject to any abuse, both physical and sexual abuse, sexual abuse only, or physical abuse only. The exposure period extended until age 11 .

Childhood physical abuse was defined as experiencing or living in fear of being pushed, grabbed, or shoved; having something thrown at you that could cause injury; being kicked, bit, or punched; being hit by an object or person with the intention to hurt; or being physically attacked, each with a frequency of more than a few times. Experienced physical abuse also included having someone you loved killed with a frequency of a few times or less, while feared physical abuse included living in fear that someone you loved would be killed or that any of the above descriptions would happen to someone else in the home, each with a frequency of more than a few times.

Experienced childhood sexual abuse was defined as being sexually assaulted with a frequency of a few times or less or having someone expose their genital parts against your will with a frequency of more than a few times. Feared childhood sexual abuse was defined as living in fear of sexual assault; someone exposing their genital parts against your will; or someone being sexual with you against your will; each with a frequency of more than a few times. Any experienced childhood abuse was defined as experiencing physical or sexual abuse as a child. Any feared childhood abuse was defined as fearing physical or sexual abuse as a child.

We also assessed the following covariates: parent smoking status, religion, social class position, childhood poverty, ancestry, race, and parent education status. Self reported information regarding race, religion, ancestry, and parent smoking status was available from the baseline questionnaire from all participants in the Harvard study of moods and cycles. Socioeconomic and demographic variables such as social class position, childhood poverty, and parent education status were obtained from the survey of interpersonal relationships. Women who met the moods and cycles criteria for depression additionally provided information regarding their earliest age of depression onset.

Social class position was initially defined by three binary variables: non-working class, working class, and wage earner not in the paid working force. Non-working class members were distinguished as households where the primary wage earner occupied a supervisory position or owned a business. In working class households, the primary wage earner worked for an institution or someone else and did not supervise other people. If the primary wage earner was unemployed, the household was identified as one where the wage earner was not in the paid labour force. These categories have been defined and validated elsewhere. ${ }^{17} 18$ Within our study cohort, only eight women were classified as not in the paid labour force. Therefore, our analysis of social class as a confounding variable is based on the risk of working class compared with non-working class people.

Childhood poverty was indicated by households where, on at least two occasions, there was not enough money to pay for food or rent or mortgage; money had to be borrowed to pay for medical expenses; there was not enough money to make ends meet; or public assistance or welfare was received. Parent education status addressed the highest level of education reached by either parent.

The main outcome of interest was smoking status as recorded at study enrolment. Participants who indicated on the study of moods and cycles baseline questionnaire that they had smoked more than 100 cigarettes in their lifetime were classified as smokers. Those who had not smoked more than 100 cigarettes were classified as non-smokers. Age of smoking onset was also recorded on the baseline questionnaire. A total of 10 (1.4\%) participants whose age of smoking onset occurred before the end of the exposure period (age 11) were excluded. To control for the effect of depression, 38 (5\%) women were restricted from analyses because their earliest onset of depression occurred before they began smoking. Within the remaining cohort, 283 (41\%) women were classified as smokers. The mean and median ages of smoking onset were both 16 years.

\section{Statistical analysis}

We first evaluated frequency distributions of all binary and categorical variables with respect to any experienced childhood abuse. Univariate logistic regression provided crude odds ratios and 95\% confidence intervals and important information for the assessment of confounding.

Parent smoking status, religion, social class position, childhood poverty, ancestry, race, and parent education status were considered as potential confounders. Variables that obtained univariate significance at the $p=0.05$ level were included in the final models. In addition, each covariate that did not achieve univariate significance was manually introduced into the model to determine if it was a confounder. The definition of a confounder was met only if the covariate was associated with childhood victimisation, an independent predictor of cigarette smoking, and not an intermediary of the causal pathway from exposure to outcome. A greater than $10 \%$ change of the effect estimate resulting from inclusion of a covariate provided additional evidence of confounding.

Three separate final models were constructed to evaluate the association of childhood victimisation and smoking. The first model evaluated the effect of any experienced childhood abuse. A second model describes the effect of both physical and sexual abuse, sexual abuse only, and physical abuse only on risk of cigarette smoking. A third and final model evaluated risk of smoking by living in fear of abuse without actual experience, experience of abuse without fear, and both experienced and feared abuse. Once confounders were identified and incorporated into the individual models, each covariate was taken out of the model one at a time and any change in the standard error estimates of the remaining predictor variables was observed. If a standard error estimate was dramatically reduced, it was considered to be indicative of collinearity. The analyses described above were performed both with and without the records of women excluded for depression.

\section{RESULTS}

There were 179 (26\%) women who reported experiencing childhood abuse. Of these, 20 (3\%) women experienced both physical and sexual abuse, 119 (17\%) experienced physical abuse only, and $40(6 \%)$ experienced sexual abuse only. A total of $108(16 \%)$ women reported fear of childhood abuse. Of women who feared childhood abuse, 15 (2\%) women feared physical and sexual abuse, 86 (13\%) feared physical abuse only, and 7 feared sexual abuse only (1\%). Within the study cohort, 505 (74\%) women reported that they never experienced abuse as a child, and 488 (71\%) women reported that they neither experienced or feared abuse as a child.

Table 1 describes demographic and socioeconomic characteristics of the study cohort and univariate predictors of childhood victimisation. Women who experienced childhood abuse were more likely to have experienced childhood poverty and come from working class families. Significant univariate predictors of childhood abuse were social class, poverty, and religion. Women who grew up in working class households were 1.7 times more likely to experience childhood abuse than women from other social classes. Women who experienced poverty in childhood were 1.9 times as 
Table 1 Sociodemographic characteristics stratified by experience of any childhood abuse among women from the Harvard study of moods and cycles, Boston, Massachusetts. Univariate odds ratios and $95 \%$ confidence intervals shown

\begin{tabular}{|c|c|c|c|c|}
\hline & $\begin{array}{l}\text { Did not experience abuse } \\
n=505\end{array}$ & $\begin{array}{l}\text { Any experienced abuse } \\
n=179\end{array}$ & OR $(95 \% \mathrm{Cl})$ & $\mathrm{p}$ Value \\
\hline \multicolumn{5}{|l|}{ Parental smoking status, n (\%) } \\
\hline Neither parent smoked & 98 (19.4) & 30 (16.8) & 1.0 & \\
\hline Mother smoked & $42(8.3)$ & $17(9.5)$ & $1.3(0.7$ to 2.7$)$ & 0.4 \\
\hline Father smoked & $154(30.5)$ & $49(27.4)$ & $1.0(0.6$ to 1.7$)$ & 0.9 \\
\hline Both parents smoked & $211(41.8)$ & $83(46.4)$ & $1.3(0.8$ to 2.1$)$ & 0.3 \\
\hline \multicolumn{5}{|l|}{ Religion, $\mathrm{n}(\%)$} \\
\hline Roman Catholic & $272(53.9)$ & $108(60.3)$ & 1.0 & \\
\hline Jewish & $57(11.3)$ & $11(6.2)$ & $0.5(0.2$ to 1.0$)$ & 0.04 \\
\hline Protestant & $139(27.5)$ & $48(26.8)$ & $0.9(0.6$ to 1.3$)$ & 0.5 \\
\hline None/Other & $37(7.3)$ & $12(6.7)$ & $0.8(0.4$ to 1.6$)$ & 0.6 \\
\hline Working class family (y), n (\%) & $165(32.7)$ & $81(45.2)$ & $1.7(1.2$ to 2.4$)$ & 0.003 \\
\hline Experienced childhood poverty $(y), n(\%)$ & $71(14.1)$ & $42(23.5)$ & $1.9(1.2$ to 2.9$)$ & 0.004 \\
\hline \multicolumn{5}{|l|}{ Ancestry, $n(\%)$} \\
\hline European & 468 (92.7) & $161(89.9)$ & 1.0 & \\
\hline Non-European & $37(7.3)$ & $18(10.1)$ & $1.4(0.8$ to 2.6$)$ & 0.3 \\
\hline \multicolumn{5}{|l|}{ Race, $\mathrm{n}(\%)$} \\
\hline White & $484(95.8)$ & $169(94.4)$ & 1.0 & \\
\hline Non-white & $21(4.2)$ & $10(5.6)$ & $1.4(0.6$ to 3.0$)$ & 0.4 \\
\hline \multicolumn{5}{|l|}{ Parent education status, n (\%) } \\
\hline Less than 12 th grade & $24(4.9)$ & $9(5.1)$ & 1.0 & \\
\hline High school degree/GED & $133(27.1)$ & $50(28.4)$ & $1.0(0.4$ to 2.3$)$ & 1.0 \\
\hline Some college/vocational school & $82(16.7)$ & 31 (17.6) & $1.0(0.4$ to 2.4$)$ & 1.0 \\
\hline BA (four years of college) & $115(23.4)$ & $45(25.6)$ & $1.0(0.5$ to 2.4$)$ & 0.9 \\
\hline Graduate degree & $137(27.9$ & $41(23.3)$ & $0.8(0.3$ to 1.9$)$ & 0.6 \\
\hline Don't know or Missing & 14 & 3 & & \\
\hline
\end{tabular}

likely to experience abuse as those who did not. Jewish women had $50 \%$ the risk of experiencing child abuse compared with Roman Catholic women. No evidence of collinearity was found between childhood abuse, religion, social class, and poverty.

Table 2 illustrates the crude and adjusted effect estimates for smoking risk by categories of experienced (rather than feared) childhood abuse. The odds of smoking were 1.4 times greater among women who did, compared with those that did not, experience any childhood abuse. Women who were both physically and sexually abused had 3.5 times the odds of smoking compared with women who did not experience any childhood abuse. Women who were sexually abused were at twice the risk of smoking while women who were physically abused did not seem to be at any increased risk for smoking.

Table 3 describes the relation between smoking risk and living in fear of abuse during childhood, with and without the experience of abuse. Living in fear of abuse did not seem to contribute greatly to smoking risk. The experience of abuse in the absence of fear of abuse was of borderline significance as a univariate predictor of smoking but lost significance after adjustment for religion, working class, and poverty. Thus, increased smoking risk was predominantly associated with experience, rather than fear, of abuse, and largely confined to sexual as compared with physical abuse.

\section{DISCUSSION}

We observed a threefold risk of smoking among women who experienced both physical and sexual abuse, and a twofold risk among women sexually abused during childhood after adjustment for religion, working class, and poverty. Our study was able to elucidate these associations because of the detailed information on type, life stage, and frequency of abuse reported in the survey of interpersonal relationships. Previous research has resorted to defining lifetime or adolescent experiences of abuse based on limited information. Such measurements are problematic for evaluating smoking risk because of characteristically early ages of smoking initiation. To accurately determine that the abuse preceded smoking onset, either a very early exposure period should be established, or information should be obtained regarding the exact age (or life stage) of victimisation and smoking onset. Our research has relied on the latter.

To look at the effect of childhood abuse on smoking risk independent of depression, we chose to restrict our analysis to women who began smoking before their first onset of depression. When the same analyses were conducted including women with a history of depression before smoking onset $(\mathrm{n}=38)$, the results illustrated similar patterns of effect. All measured variables were distributed comparably. However, religion was no longer a significant predictor of exposure status. Excluding the 38 women from analyses resulted in a

\begin{tabular}{|c|c|c|c|}
\hline & Number (\%) & Crude OR (95\%Cl) & Adjusted* OR $(95 \% \mathrm{Cl})$ \\
\hline \multicolumn{4}{|l|}{ Experienced abuse: } \\
\hline Did not experience child abuse & $505(73.8)$ & 1.0 & 1.0 \\
\hline Any child abuse & $179(26.2)$ & $1.4(1.0$ to 2.0$)$ & $1.4(1.0$ to 2.0$)$ \\
\hline Both physical and sexual abuse & $20(2.9)$ & 3.6 (1.4 to 9.7$)$ & 3.5 (1.3 to 9.4$)$ \\
\hline Physical abuse only & $119(17.4)$ & $1.1(0.7$ to 1.6$)$ & $1.0(0.7$ to 1.6$)$ \\
\hline Sexual abuse only & $40(5.9)$ & $2.3(1.2$ to 4.5$)$ & $2.2(1.1$ to 4.3$)$ \\
\hline
\end{tabular}


Table 3 Crude and adjusted ${ }^{*}$ odds ratios and $95 \%$ confidence intervals for risk of smoking by experience or fear of abuse, or both

\begin{tabular}{|c|c|c|c|}
\hline & Number (\%) & Crude OR (95\% Cl) & Adjusted* OR $(95 \% \mathrm{Cl})$ \\
\hline No experience or fear of abuse & 488 (71.3) & 1.0 & 1.0 \\
\hline $\begin{array}{l}\text { Did not experience abuse, but lived in fear } \\
\text { that abuse would occur }\end{array}$ & $17(2.5)$ & $0.4(0.2$ to 1.5$)$ & $0.4(0.1$ to 1.3$)$ \\
\hline Experienced, but did not fear abuse & $88(12.9)$ & $1.5(1.0$ to 2.4$)$ & $1.5(0.9$ to 2.4$)$ \\
\hline Experienced and feared abuse & $91(13.3)$ & $1.3(0.8$ to 2.1$)$ & $1.2(0.8$ to 1.9$)$ \\
\hline
\end{tabular}

general attenuation of effect estimates. Whereas our estimate for any experienced childhood abuse $(\mathrm{OR}=1.4)$ was of borderline significance, including women with a history of depression resulted in an odds ratio of 1.6 (CI 1.1 to 2.2). In addition, the estimate for feared abuse accompanied by experienced abuse reached an odds ratio of 1.7 (CI 1.1 to 2.6). Although we were able to observe that smoking risk was driven by experienced (rather than feared) abuse, our models of feared and/or experienced abuse were unable to achieve statistical significance without the inclusion of women who had a history of depression before smoking onset. These findings indicate that our study results are a conservative estimate of the impact of child abuse on smoking risk. It is highly probable that an alternative pathway from childhood victimisation to depression and subsequently to smoking initiation results in even greater smoking risk. Nevertheless, we have established that women who suffer childhood abuse, even in the absence of depression, are at increased risk of smoking.

Our results are consistent with previous evaluations of the association between abuse and smoking risk. ${ }^{7-10}{ }^{13}$ Anda et al evaluated adverse childhood experiences and smoking status in their 1999 retrospective analysis. Although their definition of childhood exposure extended until age 18, a sub-analysis found that sexual abuse before age 14 resulted in increased risk for smoking initiation before age 14 (OR 3.9, CI 3.2 to 4.7) and current smoking (OR 2.7; CI 2.2 to 3.3). ${ }^{19}$ However, it is unclear whether they were able to clearly distinguish the temporal relation between abuse and smoking onset. Springs and Friedrich failed to find abuse to be a significant predictor of smoking status, but instead found it to be predictive of earlier smoking onset and heavier smoking. ${ }^{5}$ In the existing literature, the question of whether physical and/or sexual abuse exhibits relatively greater or lesser influence on smoking initiation remains unresolved. We are unaware of any other work that has specifically looked at the effect of childhood physical abuse, childhood sexual abuse, or both on smoking risk. Previous studies found that physical abuse during adolescence exerted a stronger effect on smoking risk than sexual abuse $(\mathrm{OR}=3.44$ and 2.67 , respectively), and that adolescent physical and sexual assault exerted similar effects $\left(\mathrm{OR}=1.84\right.$ and 1.86 , respectively). ${ }^{8}{ }^{13}$ Within our data, it is clear that the association was predominately driven by childhood sexual abuse.

As with all retrospective, self reported information, our study may be subject to recall bias. In many cases, participants were asked to report on the events that would have occurred more than 30 years before. In addition, it was not possible to validate participants' responses in any way. The prevalence of smoking in our study cohort was high (41\%) compared with the national prevalence of smoking among women in $1998(22 \%){ }^{2}$ This may be a direct result of our inclusive definition of smoking status. However, the prevalence of early physical abuse in our cohort is consistent with estimates of other community based surveys. ${ }^{2021}$ We suspect that childhood sexual abuse may have been underreported. Within our study cohort, 9\% of women reported being sexually abused as a child. This proportion is low compared with other community based surveys of abuse that found the prevalence of childhood sexual abuse to range from $8 \%$ to $36 \%{ }^{20}{ }^{22-24}$ A final limitation to our data collection exists in the potential for experience of childhood abuse to influence participants' ability to recall initial onset of depression.

Previous research has illustrated that child abuse may lead to poor health behaviours in later life..$^{5-8} 111219$ Victimisation during childhood notably increases risk for detrimental health effects during adulthood. These effects span a broad range of psychological, physiological, and decision making outcomes. Understanding the lasting negative impact of violence on health can help us both to reject violent behaviour and to forestall negative outcomes in populations already victimised.

Smoking onset may occur as a mechanism for coping with abuse directly. ${ }^{9}$ Smoking is a means of addressing negative affect that may be either temporary or the beginnings of lasting psychopathology. Nicotine delivered through cigarette smoking is associated with neurotransmitter release known to modulate mood. ${ }^{10}$ It has been shown to reduce pain, raise mood, and decrease anxiety. Cigarette smoking initiation is strongly influenced by both psychosocial and physiological factors. ${ }^{25}$

Our study clearly shows that women who are abused as children are at increased risk for initiation of an addictive and lethal habit. We strongly suggest that additional support be generated for general abuse screening programmes and that abuse identification be recognised as a critical part of antismoking campaigns.

\section{ACKNOWLEDGEMENTS}

We appreciate the helpful comments of Dr Nancy Krieger in the preparation of this paper.

\section{Authors' affiliations}

H B Nichols, Department of Epidemiology, Harvard School of Public Health, Boston, USA

B L Harlow, Obstetrics and Gynecology Epidemiology Center, Brigham and Women's Hospital/Harvard Medical School, Boston, USA

Funding: supported by grants from the National Institutes of Health: R $01-$ MH50013 and R 01-MH577351.

Conflicts of interest: none declared.

\section{REFERENCES}

1 Archer J. Countries meet to finalize landmark agreement on international tobacco control. World Health Organisation. http://www. who.int/ mediacentre/releases/2003/prl4/en/> (accessed 16 Feb 2003).

2 Center for Disease Control and Prevention. Overview. Tobacco Information and Prevention Source (TIPS), 19 Nov 2002. http://www.cdc.gov/tobacco/ $\mathrm{sgr} / \mathrm{sgr}$ _forwomen/factsheet_tobaccouse.htm (accessed 16 Jan 2003).

3 Whitcomb D, Hook M, Alexander E. Child victimization. National Victim Assistance Academy, June 2002. http://www.ojp.gov/ovc/assist/ nvaa2002/chapter1 1.html (accessed 16 Jan 2003).

4 Center for Disease Control and Prevention. Women and smoking: a report of the Surgeon General-2001. Tobacco Information and Prevention Source (TIPS), 27 Mar 2001. http://www.cdc.gov/tobacco/issue.htm (accessed 16 Jan 2003). 
5 Springs FE, Friedrich WN. Health risk behaviors and medical sequelae of childhood sexual abuse. Mayo Clin Proc 1992;67:527-32.

6 Moeller TP, Bachmann GA, Moeller JR. The combined effects of physical, sexual, and emotional abuse during childhood: Long-term health consequences for women. Child Abuse Negl 1993;17:623-40.

7 Simantov E, Schoen C, Klein JD. Health-compromising behaviors: Why do adolescents smoke or drink? Identifying underlying risk and protective factors. Arch Pediatr Adolesc Med 2000; 154:1025-33.

8 Diaz A, Simantov E, Rickert VI. Effect of abuse on health: results of a national survey. Arch Pediatr Adolesc Med 2002;156:81 1-17.

9 Kaplan SJ, Pelcovitz D, Salzinger S, et al. Adolescent physical abuse: risk for adolescent psychiatric disorders. Am J Psychiatry 1998;155:954-9.

10 Acierno R, Kilpatrick DG, Resnick HS, et al. Violent assault, posttraumatic stress disorder, and depression: Risk factors for cigarette use among adult women. Behav Modif 1996;20:363-84.

11 Bell D, Belicki K. A community-based study of well-being in adults reporting childhood abuse. Child Abuse Negl 1998;22:681-5

12 Bensley LS, Spieker SJ, Van Eenwyk J, et al. Self-reported abuse history and adolescent problem behaviors. II. Alcohol and drug use. J Adolesc Health 1999;24:173-80.

13 Acierno R, Kilpatrick DG, Resnick H, et al. Assault, PTSD, family substance use, and depression as risk factors for cigarette use in youth: Findings from the national survey of adolescents. J Traumatic Stress 2000;13:381-96.

14 Harlow BL, Cohen LS, Otto MW, et al. Demographic, family, and occupational characteristics associated with major depression: the Harvard study of moods and cycles. Acta Psychiatr Scand 2002; 105:209-17.

15 Harlow BL, Cohen LS, Otto MW, et al. Prevalence and predictors of depressive symptoms in older premenopausal women: The Harvard study of moods and cycles. Arch Gen Psychiatry 1999;56:418-24.
16 Wise LA, Zierier S, Krieger N, et al. Adult onset of major depressive disorder in relation to early life violent victimization: a case-control study. Lancet $2001 ; 358: 881-7$.

17 Krieger N, Chen JT, Selby JV. Class inequalities in women's health: combined impact of childhood and adult social class-a study of 630 US women. Public Health 2001;115:175-85.

18 Krieger N, Okamoto A, Selby JV. Adult female twins' recall of childhood social class and father's education: a validation study for public health research. Am J Epidemiol 1998;147(7):704-708.

19 Anda RF, Croft JB, Felitti VJ, et al. Adverse childhood experiences and smoking during adolescence and adulthood. JAMA 1999;282:1652-8.

20 Weiss E, Longhurst JG, Mazure CM. Childhood sexual abuse as a risk factor for depression in women: psychosocial and neurobiological correlates. Am J Psychiatry 1999;156:816-28.

21 MacMillan HL, Fleming JE, Trocme N, et al. Prevalence of child physical and sexual abuse in the community. JAMA 1997;278:131-5

22 Nagy S, Adcock AG, Nagy MC. A comparison of risky health behaviors of sexually active, sexually abused, and abstaining adolescents. Pediatrics 1994:93:570-5.

23 Stock JL, Bell MA, Boyer DK, et al. Adolescent pregnancy and sexual risktaking among sexually abused girls. Fam Plann Perspect 1997;29:200-3, 227.

24 Heise L, Ellsber M, Gottemoeller M. Ending violence against women. Population Reports, series L, no 11. Baltimore: Johns Hopkins University School of Public Health, Population Information Program, December 1999. http://www.jhuccp.org/pr/l1 $1 / 111$ tables.shtml\#table_6 (accessed 1 May 2003)

25 Carmody TP. Affect regulation, nicotine addiction, and smoking cessation. J Psychoactive Drugs 1992;24:111-22. 